\title{
Avaliação de Desempenho Mecânico de Parede com Blocos Fabricados com Resíduos de Gesso e Fibra de Celulose
}

\author{
Evaluation of Mechanical Performance of Wall with Blocks Manufactured from Gypsum \\ and Cellulose Fibers.
}

\section{Deoclebson Pereira da Silva ${ }^{1}$}

\section{Clóvis Veloso de Santana ${ }^{2}$ (D) orcid.org/0000-0001-5727-2427}

\section{Leila Cristina Nunes Ribeiro ${ }^{3}$ (b orcid.org/0000-0001-6991-0748}

\author{
${ }^{1}$ Escola Politécnica de Pernambuco, Universidade de Pernambuco, Recife, Brasil, \\ ${ }^{2}$ Instituto Federal do Amapá, Macapá, Brasil, \\ ${ }^{3}$ Instituto Federal do Amapá, Macapá, Brasil, \\ E-mail do autor principal: clovisvelososantana@hotmail.com
}

\section{Resumo}

Atualmente tem-se debatido com recorrência sobre os impactos ambientais negativos causados pelas mais diversas atividades humanas, e, notadamente, a construção civil se apresenta como um setor protagonista neste debate. Esse segmento gera muitos resíduos provenientes de suas atividades, o que tem trazido uma grande preocupação com a destinação desses entulhos. Essa preocupação é válida, segundo a literatura, visto que a preservação e a busca de novas técnicas de produção mais limpa (PML) visam garantir o suprimento das necessidade das gerações futuras. Observando essa tendência, o presente trabalho pretendeu avaliar o desempenho mecânico de uma parede realizada com blocos que foram produzidos com mistura de gesso natural $(70 \%)$, resíduo de gesso (30\%) e com o acréscimo de fibra de celulose. Foram realizados quatro ensaios em uma parede protótipo sem função estrutural, seguindo a norma NBR 15.575-4 (ABNT, 2013). A parede apresentou desempenho superior em três testes (ensaio de carga suspensa, impacto de corpo duro e impacto de corpo mole) e foi reprovada em um ensaio (ensaio de rede).

Palavras-Chave: Gesso. Resíduo de gesso. Blocos de gesso.

\begin{abstract}
Nowadays, more and more debate is being carried out on the negative environmental impacts caused by the most diverse human activities, in particular civil construction is a leading sector in this debate. This segment generates a lot of waste from its activities, which has brought great concern to the disposal of these waste. This concern is valid, according to the literature, since the preservation and the search for new techniques of clean production aim to assurance the supply of the needs of future generations. Observing this trend, the present work aimed to evaluate the mechanical performance of a wall made with blocks that were produced with a mixture of natural gypsum (70\%), gypsum waste (30\%) and cellulose fiber addition. Four tests were carried out on a prototype wall without structural function, following the norm NBR 15575-4 (ABNT, 2013). The wall showed superior performance in three tests (suspense load test, hard body impact and soft body impact) and was disregarded in one test (inclined suspended load).
\end{abstract}

Key-words: Gypsum. Waste. Gypsum block. 


\section{Introdução}

O gesso é um material de construção que apresenta uma gama de aplicações na construção civil moderna. No Brasil, este material apresenta excelentes propriedades; em particular, tal cenário tem se justificado pelas características da matéria prima que o origina (gipsita). A gipsita é um mineral encontrado em depósitos de origem evaporítica, disponível em várias partes do mundo, com destaque ao Brasil, que é o $11^{\circ}$ maior produtor mundial [1]. A maior parte da produção brasileira se encontra na Região do Araripe, compreendendo os Municípios de Araripina, Bodocó, Ipubi, Ouricuri e Trindade. O minério encontrado nesse local apresenta elevado grau de pureza, cerca de 93\% [2].

Apesar de o setor gesseiro mostrar-se como um setor promissor, do ponto de vista mercadológico, alguns autores indicam que existem alguns impasses que o impedem de ser inserido como um seguimento ambientalmente sustentável. Um destes fatores é o alto volume de resíduos gerados na cadeia produtiva gesseira. Somente na Construção civil, estima-se que correspondam entre 4 a 15\% dos Resíduos da Construção e Demolição (RCD) [3]. Na etapa de produção e transporte do material também são evidenciados altos volumes de resíduos, conquanto, não existem dados recentes que estimem tal volume.

As principais preocupações ambientais associadas com o descarte e a eliminação dos resíduos de gesso são a lixiviação das águas superficiais e subterrâneas e a geração de poeira no ar [4]. Somado a isso, outros autores ressaltam que esse tipo de resíduo ocupa grandes áreas e exigem gastos de longo prazo para manutenção e monitoramento [5]. No Brasil, os resíduos de gesso não podem ser depositados em aterros, por conta da sua reatividade, uma vez que o sulfatos podem reagir com substâncias orgânicas formando gases tóxicos [5] [6].

Alguns estudos recentes tem demostrado que é possível reciclar o gesso e reinseri-lo na cadeia produtiva, sem demostrar prejuízos consideráveis do ponto de vista técnico, tal como mostram os trabalhos de Bardella [7], Geraldo [6] e Pinheiro [8] que através de um processo físico-químico, conseguem, em alguns casos, ganho de resistência mecânica do material reciclado. Por outro lado, os mesmos autores apontam perda de trabalhabilidade do novo material e diminuição do tempo de pega.

A partir da reciclagem apenas física (cominuição do gesso) e reinserção parcial do resíduo ao gesso convencional, autores como Bernhoeft, Gusmão e Póvoas [9], Póvoas et. al [10] e Vieira, Trovão e Teles [11] conseguem obter material com bom aproveitamento físico e mecânico.

A corroboração da aplicabilidade do gesso reciclado é abordado em Santana [12] quando ao utilizar metodologia semelhante a Pinheiro [8], Bardella [7] e Geraldo [6], em um processo industrial, produz blocos de gesso reciclado para vedações verticais, e verifica que tal material atende satisfatoriamente aos requisitos e critérios mecânicos (ensaio de impacto de corpo duro, mole e resistência à fixação de peças suspensas) estabelecidos na norma de desempenho NBR 15575-4 [13].

Partindo desse panorama, o presente trabalho pretende analisar por meio de ensaios laboratoriais, o desempenho de paredes com blocos produzidos com gesso, resíduos de gesso e fibra de celulose. A referida técnica pode-se apresentar como uma possibilidade de reaproveitamento de materiais que seriam descartados, reduzindo assim, a poluição ambiental. 


\section{Objetivos \\ 2.1 Objetivo Geral}

Verificar o desempenho de paredes desenvolvidas com blocos de gesso produzidos com porcentagem de material reciclado (cerca de $30 \%$ ) e fibra de celulose (proveniente de descarte de material da indústria de celulose) atendem as exigências da norma NBR 15575-4 [13].

\subsection{Objetivos específicos}

Para o cumprimento do objetivo geral, os seguintes objetivos específicos serão necessários:

- Descrever as melhores práticas para elevação de alvenaria protótipo em laboratório;

- Verificar o desempenho quanto aos ensaios de impacto de corpo duro, através de fixação de cargas suspensas e impacto de corpo mole.

\section{Materiais e Métodos}

Os materiais utilizados nesta pesquisa encontram-se no Quadro 1.

Quadro 1: Material utilizado nos ensaios.

\begin{tabular}{|l|}
\hline \multicolumn{2}{|c|}{ Materiais } \\
\hline Blocos de gesso vazado $(66,7 \mathrm{~cm} \times 50 \mathrm{~cm} \times$ \\
$10 \mathrm{~cm}) \mathrm{com} 30 \%$ de resíduo de gesso e fibra \\
de celulose na sua composição (método de \\
$\begin{array}{l}\text { produção não fornecido pela empresa } \\
\text { fabricante). }\end{array}$ \\
\hline \multicolumn{2}{|c|}{ Aesso cola potável } \\
\hline Espuma de poliuretano expandido \\
\hline
\end{tabular}

Para a elevação da parede, que apresentava dimensões de 2,85 $\mathrm{m}$ de largura por 2,62 $\mathrm{m}$ de altura. Inicialmente o gesso cola foi colocado em um balde com água potável e misturado mecanicamente com batedor de argamassa, e em seguida foi levado para aplicação direta no bloco.

Por sua vez, o bloco teve todas as suas áreas de contato limpas, para então ser posicionado. Com o local para a parede limpo, os blocos foram preenchidos com cola em todas as suas faces de contato e posicionados.

Toda a área de encaixe dos blocos foi preenchida com a cola, e na execução o prumo e o alinhamento foram checados na medida que cada peça era posicionada, bem como, a colocação de telas nas laterais da vedação. $\mathrm{Na}$ etapa final, foi colocado espuma de poliuretano expandido na parte superior para contribuir na fixação da parede. A parede ficou posicionada conforme a imagem abaixo (Figura 1).

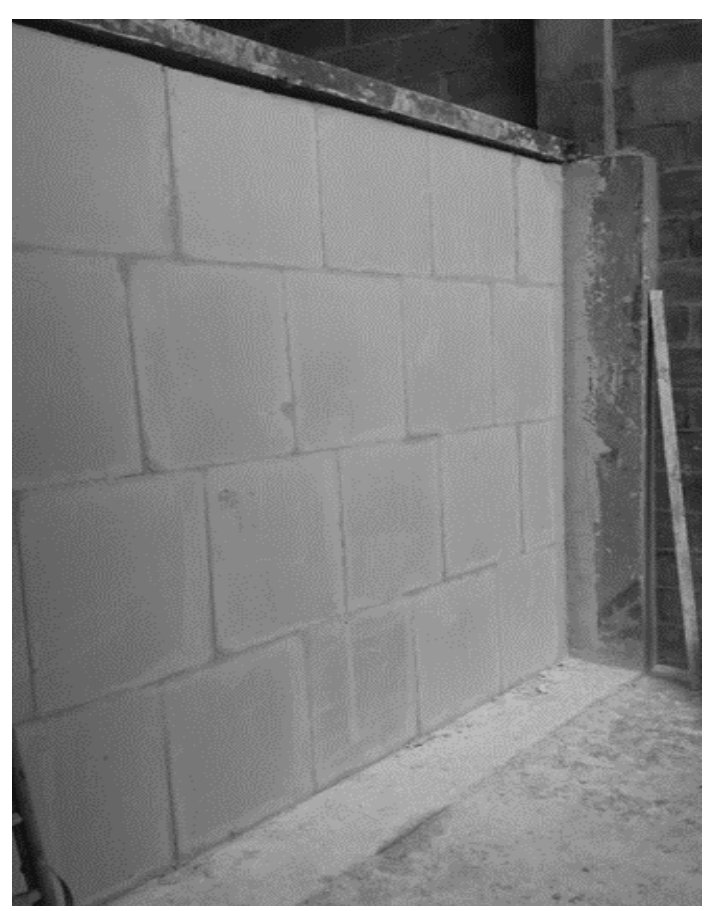

Figura 1 - Parede para ensaios.

Fonte: O autor.

Os ensaios realizados encontram-se em ordem no Quadro 2.

Quadro 2: Resumo de ensaios.

\begin{tabular}{|c|c|c|}
\hline Ordem & Ensaio & Referênca \\
\hline 1 & $\begin{array}{c}\text { Impacto de } \\
\text { corpo duro }\end{array}$ & $\begin{array}{c}\text { NBR 15575-4 } \\
{[13]}\end{array}$ \\
\hline 2 & $\begin{array}{c}\text { Carga suspensa } \\
\text { (mão francesa) }\end{array}$ & $\begin{array}{c}\text { NBR 15575-4 } \\
{[13]}\end{array}$ \\
\hline 3 & Rede & NBR 15575-4 \\
& [13] \\
\hline 4 & corpo mole & NBR 15575-4 \\
& \multicolumn{2}{|c|}{ 13] } \\
\hline
\end{tabular}




\subsection{Ensaio de Impacto de Corpo Duro}

Este ensaio consistiu, no primeiro momento, em permitir o impacto de um corpo com massa de $0,50 \mathrm{~kg}$, largado do repouso a uma altura de $0,90 \mathrm{~m}$ formando um pêndulo, produzindo uma energia cinética de 2,50 J, em dez pontos diferentes. As cavidades deixadas nos dez pontos são medidas com auxílio de paquímetro, e verificado se a mossa ultrapassou ou não ao limite prescrito na NBR 15575-4 [13] (Figura 2).

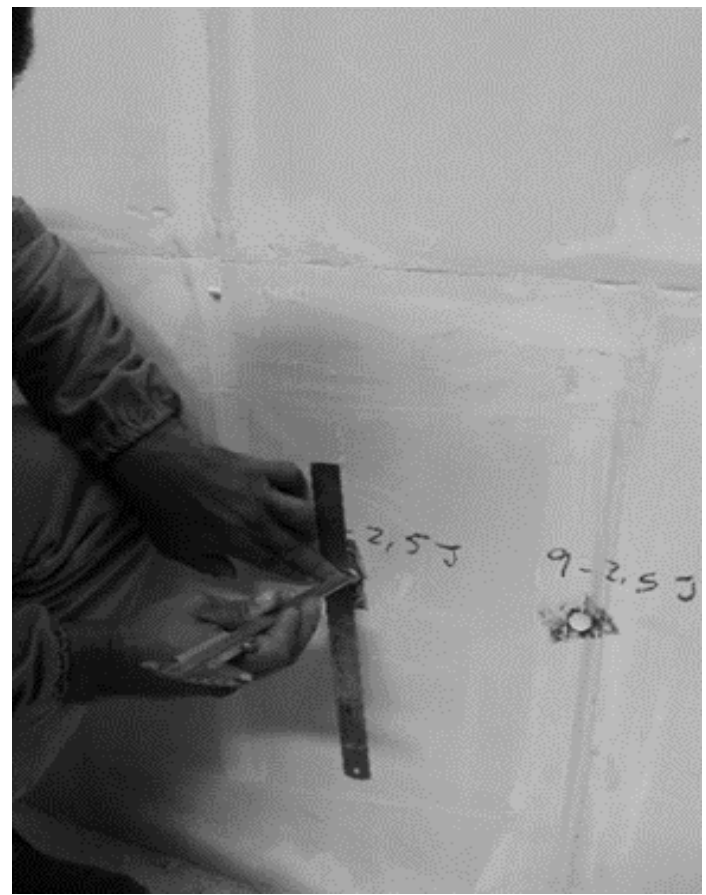

Figura 2: Medição das cavidades do ensaio de corpo duro.

Fonte: O autor.

Na sequência, de forma semelhante, uma esfera com $1,00 \mathrm{~kg}$, foi solta para produção de energia de 10,00 J, em dez pontos distintos, conforme a NBR 15575-4 [13]. A figura 3 mostra as mossas produzidas para energia de $2,50 \mathrm{~J}$ (parte inferior) e $10 \mathrm{~J}$ (parte superior).

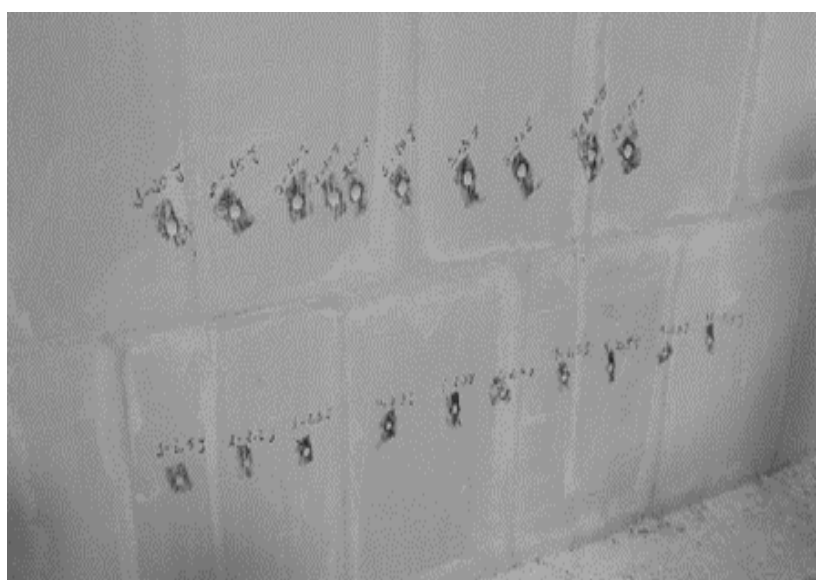

Figura 3 - Mossas do ensaio de corpo duro.

Fonte: $O$ autor.

\subsection{Ensaio de Carga Suspensa}

O ensaio de cargas provenientes de peças suspensas foi reproduzido na mesma parede em que se realizou o ensaio de impacto de corpo duro, dessa forma a parede recebeu uma carga vertical máxima e excêntrica de 120 kN, aplicadas em uma mão-francesa padrão. $\mathrm{O}$ tempo de permanência escolhido para o ensaio foi de longa duração, conforme a NBR 155754 [13].

Para se medir os resultados, dois equipamentos foram utilizados na face contraria à mão francesa, de forma que fosse possível efetuar a leitura dos deslocamentos. Um deles foi o paquímetro, para medição do deslocamento instantâneo, e o outro o relógio comparador, para medir o deslocamento residual (Figura 4). 


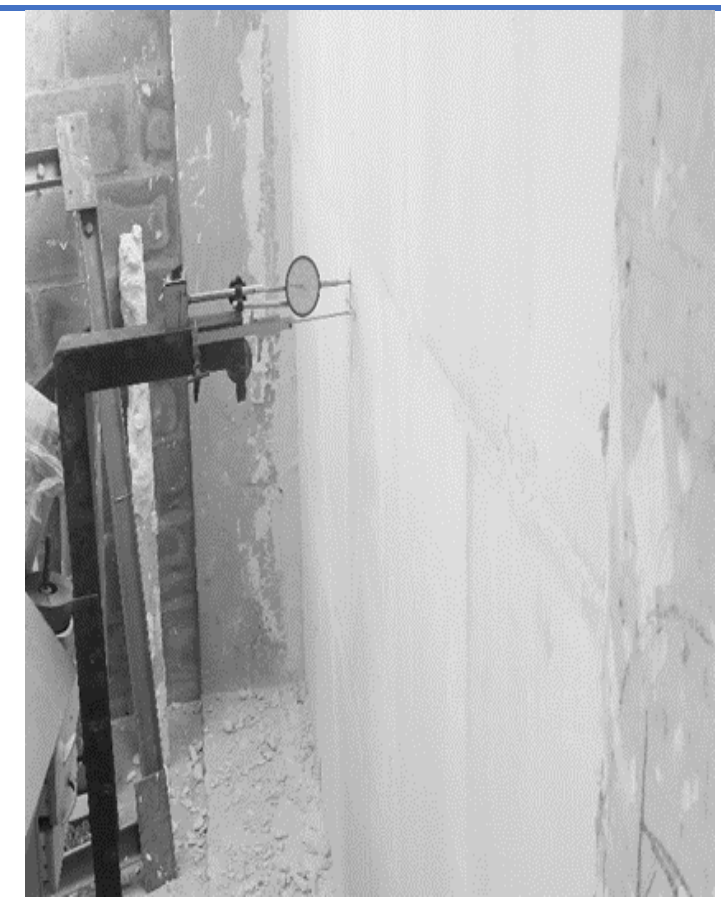

Figura 4 - Equipamentos de medição.

Fonte: $O$ autor.

O ensaio começou com a leitura inicial de ambos os equipamentos, logo em seguida pesos de $5,00 \mathrm{~kg}$ foram colocados a cada 3 minutos, de forma a se chegar aos $80,00 \mathrm{~kg}$ na primeira etapa. As etapas seguintes foram realizadas após o período de 24 horas. Ao todo foram realizadas três leituras dos equipamentos com os mesmos $80,00 \mathrm{~kg}$ suspensos.

A parede suportou essa primeira carga então, de forma similar, foram acrescentados $20,00 \mathrm{~kg}$, chegando-se aos $100 \mathrm{~kg}$, para novamente ser feita a medição. De forma satisfatória foram suportados os $100,00 \mathrm{~kg}$ e então a última parte foi a colocação de mais carga até se chegar os $120,00 \mathrm{~kg}$, para então ser efetuado o a medição do último valor de deslocamento após 24 hrs conforme a a NBR 15575-4[13] (Figura 5).

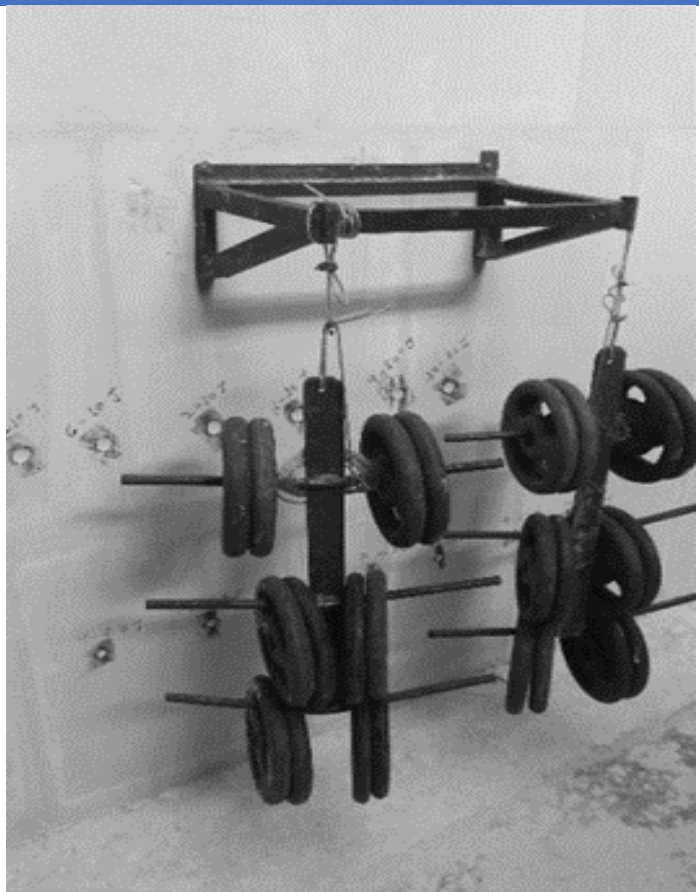

Figura 5 - Fixação de peças suspensas.

Fonte: $\mathrm{O}$ autor.

\subsection{Ensaio de Rede}

Para realização do ensaio, foram realizados dois furos com auxílio de serra copo, e imediatamente foi colocado gesso cola e uma bucha de parafuso para posterior fixação do armador de rede.

Em seguida, foi montada uma estrutura de simulação da força atuante de uma rede comum (Figura 6). A inclinação entre o cabo e a face da parede é de $60^{\circ}$, gerando carga que pode ser decomposta em componentes vertical e horizontal. 


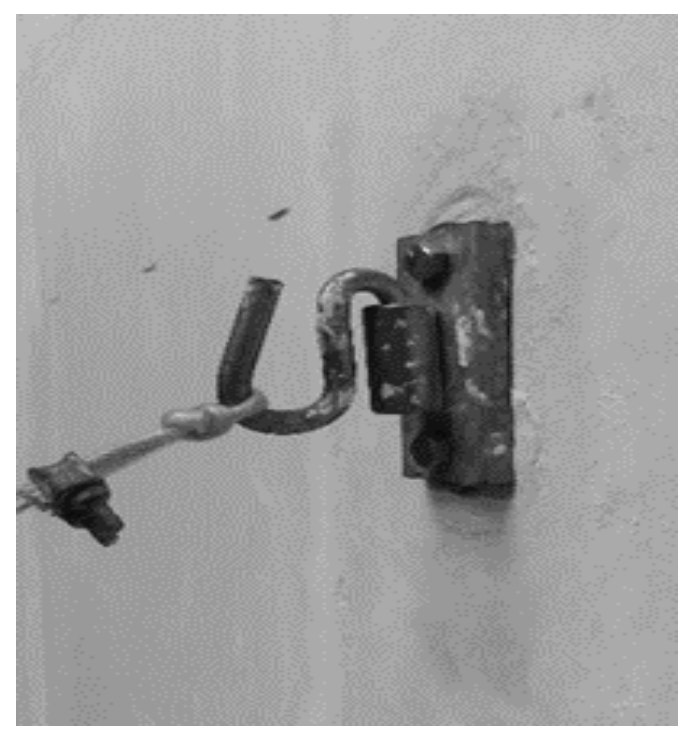

Figura 6 - Armador de rede fixo por parafusos. Fonte: $\mathrm{O}$ autor.

A estrutura destinada ao ensaio foi posicionada em frente a parede, e de forma semelhante ao ensaio de carga suspensa, anilhas com massa de $5,00 \mathrm{~kg}$ foram colocadas uma por uma com intervalo de 3 minutos, até se chegar aos 200,00 kg (Figura 7).

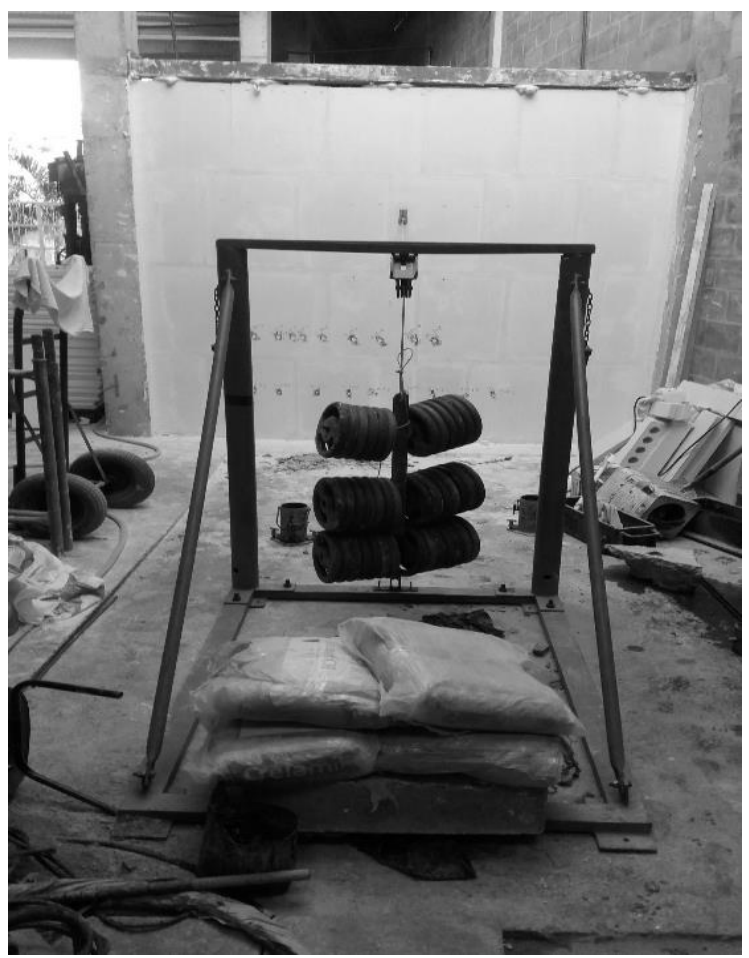

Figura 7 - Estrutura carregada com $200 \mathrm{~kg}$. Fonte: $\mathrm{O}$ autor.
Concluída a colocação dos pesos, esperouse 24 horas para ser feito a checagem (se houve algum rompimento ou desgaste que caracterizasse reprovação).

\subsection{Ensaio de Impacto de Corpo Mole}

No ensaio de impacto de corpo mole, como no ensaio de carga suspensa, um paquímetro e um relógio medidor foram posicionados atrás da face de impacto para medição dos deslocamentos. Este ensaio é o último a ser realizado, pois verifica o estado último da vedação vertical, impossibilitando outros testes de desempenho.

Em um primeiro momento, um saco de areia de 40,00 kg semelhante ao utilizado em treinos de boxe foi posicionado bem próximo a parede. Esse equipamento estava suspenso por cabos ligados à uma estrutura especial para o ensaio (Figura 8), que permitia fazer com que o saco fosse levantado $(15,00 \mathrm{~cm})$ fazendo um pêndulo e solto do repouso.

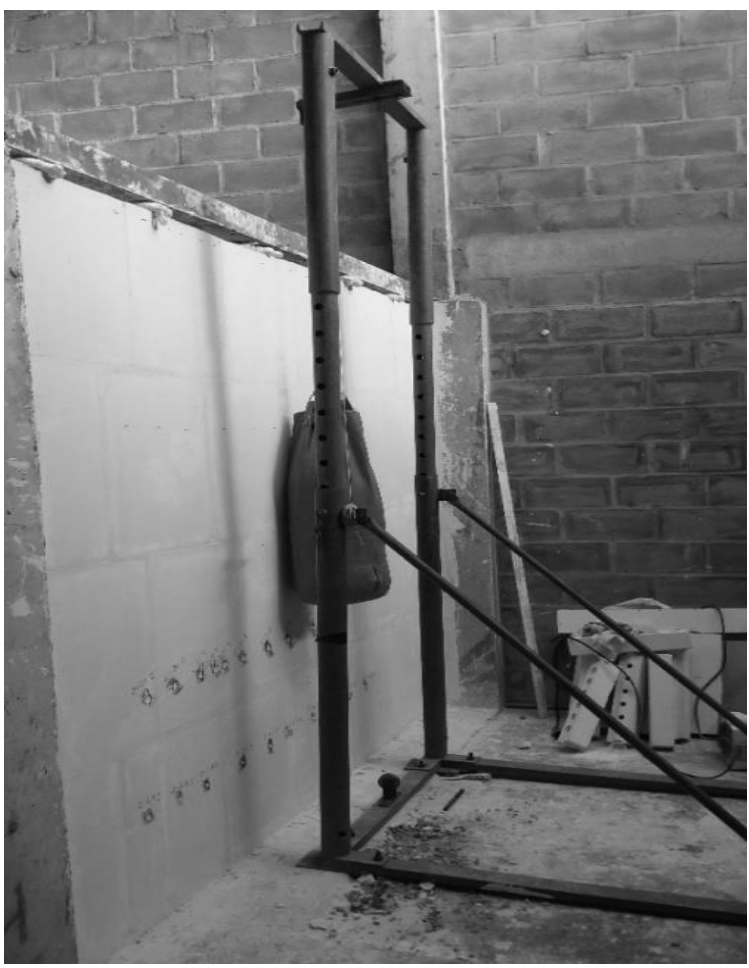

Figura 8 - Saco de areia suspenso por cabos. Fonte: O autor. 
Antes do choque, os equipamentos de medição foram lidos, e após o choque foram feitas novas leituras para verificar o deslocamento. As energias de impacto foram realizadas conforme prescreve a NBR 15575-4 [13] (Figura 9).

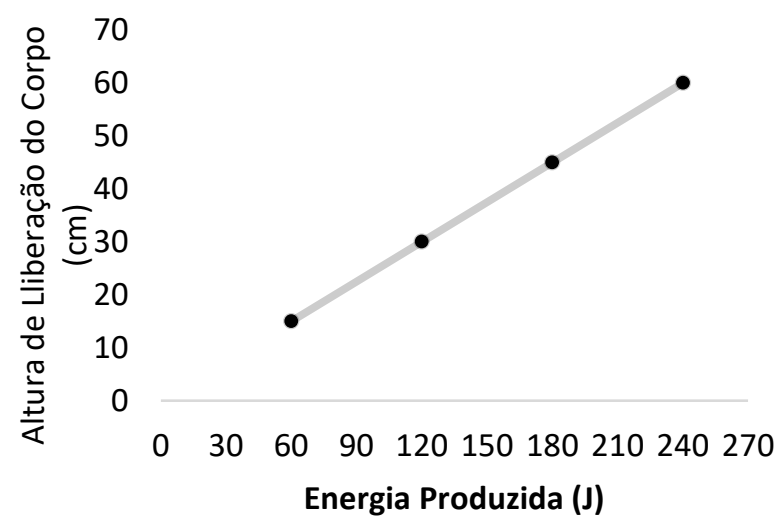

Figura 9 - Energias de impactos produzidas. Fonte: O autor.

\section{Resultados}

\subsection{Ensaio de Impacto de Corpo Duro}

A Tabela 1 apresenta os resultados dos impactos com a esfera de $0,50 \mathrm{~kg}$, que produziu 2,50 $\mathrm{J}$ de energia. Esses resultados caracterizam a profundidade da mossa provocada pelo contato do corpo com a parede. A norma estabelece que a profundidade não deve ultrapassar os 2,00 mm [2].

Tabela 1 - Resultados do ensaio de impacto de corpo duro

\begin{tabular}{c|c}
$\begin{array}{c}\text { Número do } \\
\text { impacto }\end{array}$ & $\begin{array}{c}\text { Profundidade } \\
\text { da mossa }(\mathbf{m m})\end{array}$ \\
\hline 1 & 1,40 \\
\hline 2 & 1,10 \\
\hline 3 & 1,40 \\
\hline 4 & 1,30 \\
\hline 5 & 1,50 \\
\hline 6 & 1,40 \\
\hline 7 & 1,70 \\
\hline 8 & 1,40 \\
\hline 9 & 1,30 \\
\hline 10 & 1,60 \\
\hline
\end{tabular}

Para energia de 10,00 J não houve transpassamento da esfera, muito menos comprometimento estrutural da parede. Sendo assim, considera-se que a parede atendeu ao nível superior de desempenho, conforme a NBR 15575-4 [13].

\subsection{Ensaio de Carga Suspensa}

A NBR 15.575-4 [13] estabelece que a vedação não pode apresentar fissuras ou destacamentos após o ensaio. Essa norma também estabelece que o deslocamento horizontal instântaneo (dh) não deve ser maior que a altura " $h$ " da parede dividido por 500 e o deslocamento horizontal residual (dhr) não deve ultrapassa a relação altura da parede " $h$ " dividido por 2500.

Sabendo-se que a altura " $h$ " da parede foi de $2590 \mathrm{~mm}$, verificou-se que o dh máximo foi de $5,18 \mathrm{~mm}$ e o dhr foi de $1,04 \mathrm{~mm}$ para a parede em verificação. As leituras efetuadas durante a aplicação das cargas e após as 24 horas (ensaio de longa duração) estão dispostas no Quadro 3.

Quadro 3: Resultados das leituras efetuadas.

\begin{tabular}{|c|c|c|}
\hline \multicolumn{2}{|c|}{$\begin{array}{c}\text { Leituras efetuadas pelos equipamentos } \\
\text { em mm }\end{array}$} \\
\hline \multirow{2}{*}{ Primeira Leitura } & $\begin{array}{c}\text { Paquímetro } \\
\text { (dh) }\end{array}$ & 25,11 \\
\cline { 2 - 3 } & $\begin{array}{c}\text { Relógio medidor } \\
\text { (dhr) }\end{array}$ & 79,50 \\
\hline \multirow{2}{*}{$\begin{array}{c}\text { Após 24 horas } \\
\text { com 80,00 kg }\end{array}$} & $\begin{array}{c}\text { Paquímetro } \\
\text { (dh) }\end{array}$ & 25,11 \\
\cline { 2 - 3 } & $\begin{array}{c}\text { Relógio medidor } \\
\text { (dhr) }\end{array}$ & 79,50 \\
\hline \multirow{2}{*}{ Após 24 horas } \\
com 100,00 kg & $\begin{array}{c}\text { Paquímetro } \\
\text { (dh) }\end{array}$ & 25,11 \\
\cline { 2 - 3 } & $\begin{array}{c}\text { Relógio medidor } \\
\text { (dhr) }\end{array}$ & 79,50 \\
\hline \multirow{2}{*}{ Após 24 horas } & $\begin{array}{c}\text { Paquímetro } \\
\text { (dh) }\end{array}$ & 25,11 \\
\cline { 2 - 3 } com 120,00 kg & $\begin{array}{c}\text { Relógio medidor } \\
\text { (dhr) }\end{array}$ & 79,50 \\
\hline
\end{tabular}

A partir do Quadro 3 é possível observar que a parede atendeu ao desempenho superior, pois as leituras permaneceram constantes, garantindo que o deslocamento horizontal e o

http: / / dx.doi.org/10.25286/repa.v4i1.940 
deslocamento residual não fossem ultrapassados. A vedação não apresentou fissuras ou destacamentos, condição normativa que foi atendida satisfatoriamente.

\subsection{Ensaio de Rede}

Para este ensaio a norma estabelece que a parede deve suportar uma carga de $200,00 \mathrm{~kg}$ com esforço semelhante ao produzido por uma rede. Como resultado, a parede não pode apresentar qualquer dano, bem como, o destacamento do dispositivo de fixação.

A vedação testada não atendeu ao nível de desempenho, pois houve um desprendimento do armador de rede à parede (Figura 10). Sendo assim, a parede foi reprovada neste ensaio e sua reprodução em condições de uso residencial não é recomendada para a carga de $200 \mathrm{~kg}$ e o sistema de fixação adotado.

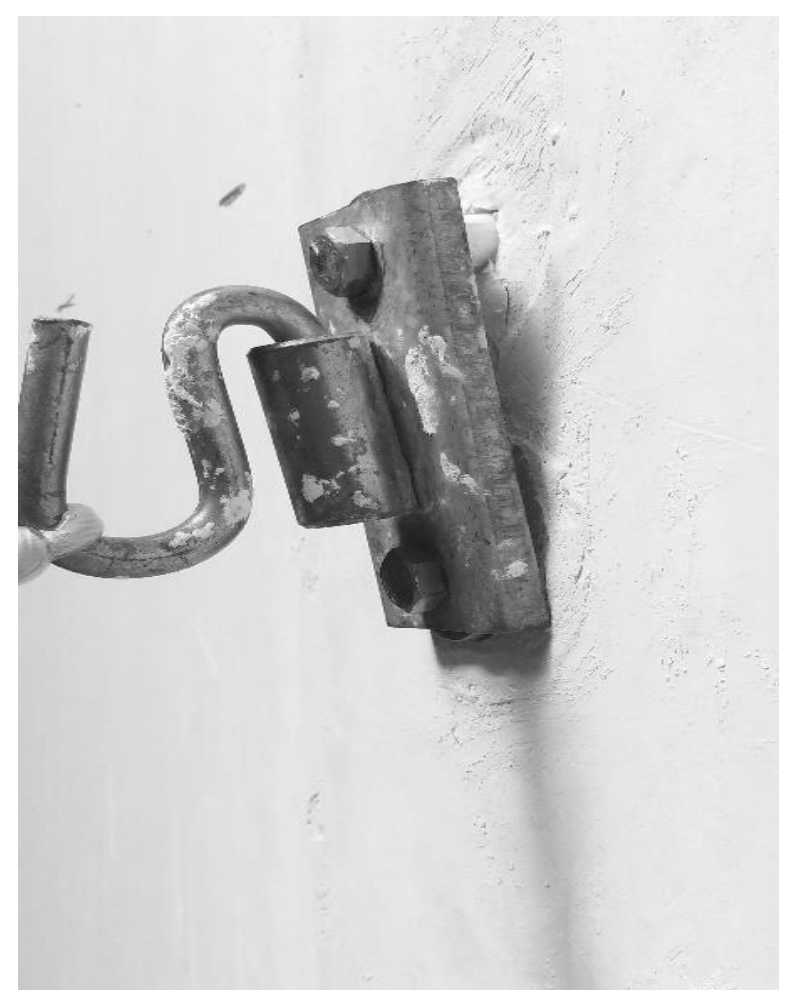

Figura 10 - Destacamento do armador de rede. Fonte: $\mathrm{O}$ autor.

\subsection{Ensaio de Impacto de Corpo Mole}

A norma estabelece os requisitos descritos no Quadro 4, levando-se em conta a energia de impacto em vedação vertical interna sem função estrutural [2].

Quadro 4: Critérios para ensaio de corpo mole.

\begin{tabular}{|c|c|}
\hline $\begin{array}{c}\text { Energia de } \\
\text { impacto (J) }\end{array}$ & Critério de desempenho \\
\hline 60 & Não ocorrência de falhas \\
\hline 120 & $\begin{array}{c}\text { Não ocorrência de falhas } \\
\text { Limite de deslocamentos: } \\
\mathrm{dh}<\mathrm{h} / 125 \\
\mathrm{dhr}<\mathrm{h} / 625\end{array}$ \\
\hline 180 & $\begin{array}{r}\text { São permitidas falhas } \\
\text { localizadas }\end{array}$ \\
\hline 240 & Não ocorrência de ruína \\
\hline
\end{tabular}

Para o impacto de $60 \mathrm{~J}$, a vedação não apresentou nenhuma fissura;

Para o impacto de $120 \mathrm{~J}$, não houve nenhuma falha e todos os deslocamentos estavam dentro do limite permitido, sendo: o deslocamento horizontal ( $\mathrm{dh}$ ) igual a $1,40 \mathrm{~mm}$ (abaixo do limite de $20,72 \mathrm{~mm}$ ) e o deslocamento horizontal residual igual a 0,02 $\mathrm{mm}$ (abaixo do limite de 4,14 $\mathrm{mm}$.

Para o impacto de $180 \mathrm{~J}$, ocorreram algumas pequenas fissuras que não caracterizaram reprovação. Essas falhas são mostradas nas Figuras 11, 12 e 13.

Para o impacto de $240 \mathrm{~J}$, a vedação permaneceu na posição sem nenhuma quebra ou danos.

Diante dos resultados é possível afirmar que a vedação atendeu ao nível superior de desempenho exigido pela norma NBR 15575-4 [13]. 


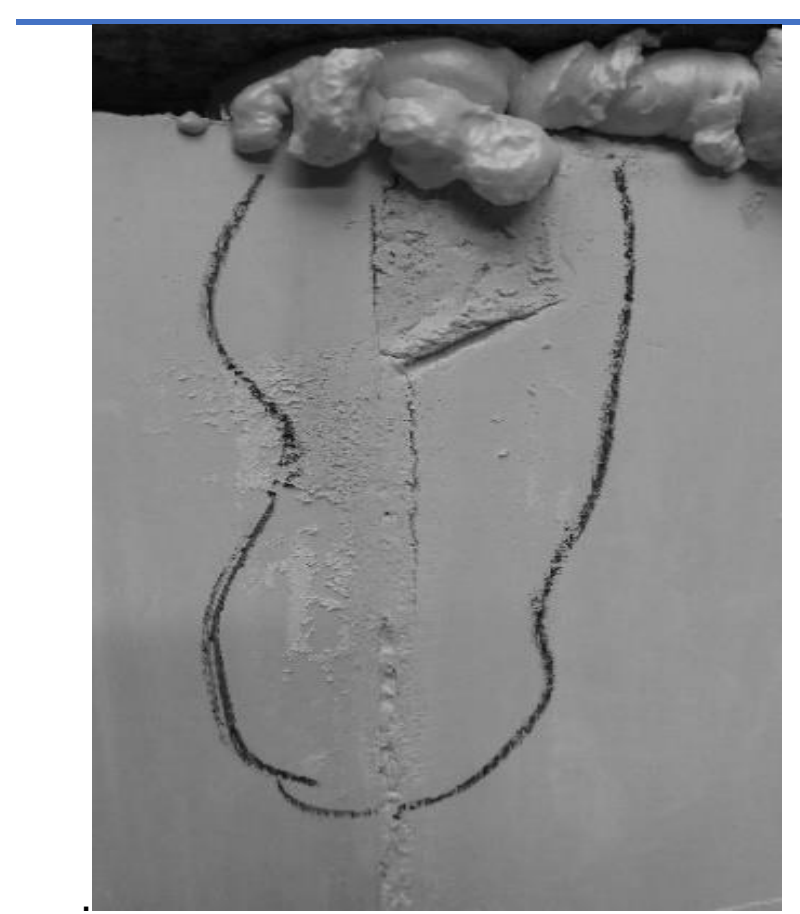

Figura 11 - Fissura provocada por impacto de corpo mole.

Fonte: $\mathrm{O}$ autor.

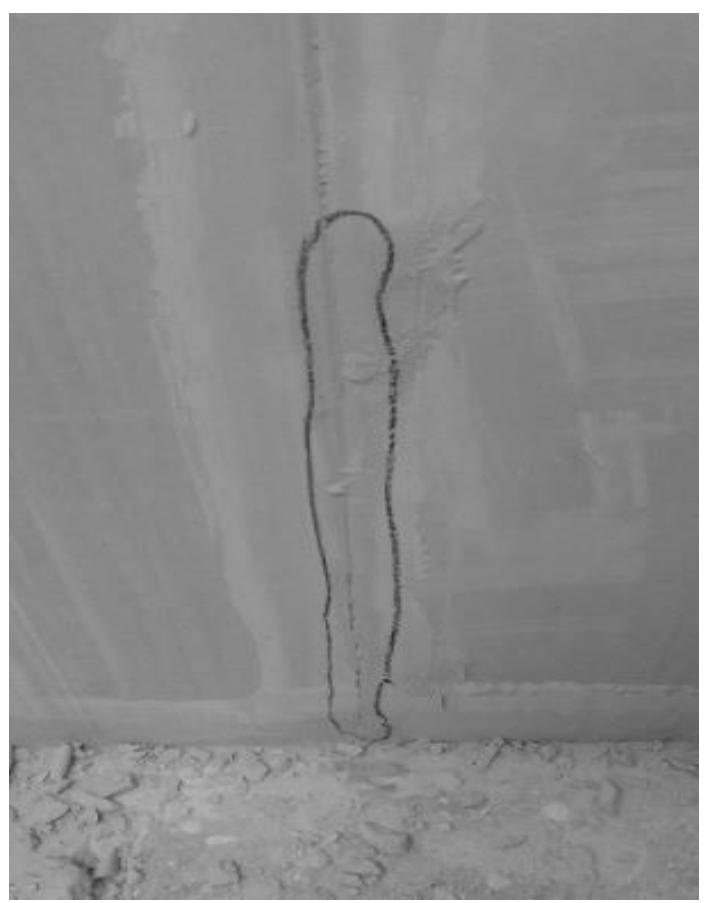

Figura 12 - Fissura provocada por impacto de corpo mole.

Fonte: $\mathrm{O}$ autor.

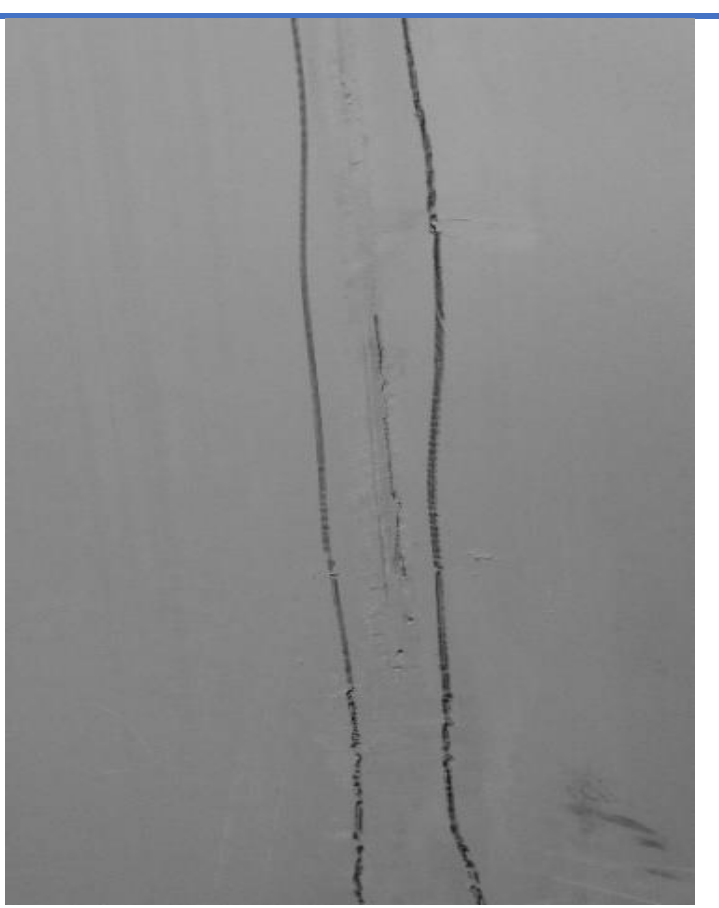

Figura 13 - Fissura provocada por impacto de corpo mole.

Fonte: $\mathrm{O}$ autor.

O Quadro 3 resume os resultados dos ensaios feitos na alvenaria de blocos de gesso, resíduo de gesso e resíduo de celulose:

Quadro 4: Resumo de ensaios.

\begin{tabular}{|c|c|}
\hline Ensaio & Situação \\
\hline $\begin{array}{c}\text { Impacto de corpo } \\
\text { duro }\end{array}$ & $\begin{array}{c}\text { Aprovado } \\
\text { (desempenho } \\
\text { superior) }\end{array}$ \\
\hline $\begin{array}{c}\text { Carga suspense } \\
\text { (mão francesa) }\end{array}$ & $\begin{array}{c}\text { Aprovado } \\
\text { (desempenho } \\
\text { superior) }\end{array}$ \\
\hline Rede & Reprovado \\
\hline $\begin{array}{c}\text { Impacto de corpo } \\
\text { mole }\end{array}$ & $\begin{array}{c}\text { Aprovado } \\
\text { (desempenho } \\
\text { superior) }\end{array}$ \\
\hline
\end{tabular}

\section{Conclusões}

A vedação vertical interna utilizada nesta pesquisa apresentou desempenho superior para os ensaio de cargas suspensas, impacto de corpo mole e corpo duro conforme os requisitos e critérios mencionados na norma NBR 15.575-4 [13].

No ensaio de dispositivo de rede, no qual a vedação testada não obteve aprovação http://dx.doi.org/10.25286/repa.v4i1.940 
segundo a NBR 15.575-4 [13], foi possível constatar que não houve nenhum dano à parede após o término do teste, o que evidencia que a forma de fixação do armador de rede teve grande interferência no resultado final, pois ocorreu somente um desprendimento parcial do armador no local do furo preenchido com gesso cola. Para posteriores reproduções do ensaio de dispositivo de rede, é aconselhável o estudo de outras técnicas para fixação do armador de rede, permitindo assim que a carga pontual se distribua por todo o elemento parede.

De acordo com os ensaios com as características descritas, é possível apontar que a vedação vertical interna em blocos de gesso, resíduo (30\%) e fibra de celulose, pode ser uma solução possível para utilização em edificações habitacionais, pois apresenta bom indicativo de desempenho mecânico. Certamente, ensaios de durabilidade, isolamento térmico, estanqueidade à água e desempenho acústico devem ser realizados para reforçar tal entendimento.

Reforça-se que o desempenho mencionado, aplicou-se somente a um tipo de amostragem, que foi fornecido por um processo de fabricação não divulgado pela empresa fornecedora. Dessa maneira, a repetitividade dos ensaios, inclusive em condições ambientais mais desfavoráveis (úmidas) pode fornecer resultados diferentes, porém mais realísticos e estatisticamente satisfatórios.

\section{Referencias}

[1] DEPARTAMENTO NACIONAL DE PRODUÇÃO MINERAL - DNMP. Sumário Mineral. 2013. Disponível em: < http://www.dnpm.gov.br/dnpm/sumarios/gi psita-sumario-mineral2014>. Acesso em: 4 abr. 2017.

[2] A. Q. Filho, A. A. Amorim, J. O. Dantas. Gipsita, Sumário Mineral, Brasilia, páginas 72-73, 2015.
Characteristics of Gypsum Recycling in Different Cycles. International Journal of Engineering and Technology - IACSIT, v.7, n.3, 2015.

[4] N. R. Mbhele, W. Van Der Merwe, J. P. Maree, D. Theron. Recovery of Sulphur from Waste Gypsum. In: Abstracts of the International Mine Water Conference". 19-23 October 2009, pp. 622-630.

[5] H. Tayibi, M. Choura, F. A. López, F. J. Alguacil, A. López-Delgado. Environmental impact and management of phosphogypsum. J. Environ. Manage. 90 (8), 23772386, 2009.

[6] R. H. Geraldo, S. M. M. Pinheiro, J. S. Silva, H. M. C. Handrade, J. Dweck, J. P. Gonçalves, G. Camarini. Gypsum plaster waste recycling: A potential environmental and industrial solution. Journal of Cleaner Production, v. 164, p.288-300, 2017.

[7] P. S. Bardella. Análise das Propriedades de Pastas de Gesso de Construção Reciclado. 2011. 235 f. Tese (Doutorado) - Faculdade de Engenharia Civil, Arquitetura e Urbanismo da Universidade Estadual de Campinas, 2011.

[8] PINHEIRO, S. M. M. Gesso Reciclado: avaliação de propriedades para uso em componentes. 97-125p. Tese (Doutorado) Universidade Estadual de Campinas, Campinas, 2011.

[9] L. F. Bernhoeft, A. D. Gusmao, Y. V. T. Póvoas. Influência da adição de resíduo de gesso no calor de hidratação da argamassa de revestimento interno. Ambiente Construído (Online), v. 11, p. 189-199, 2011.

[10] Y. V. T. Póvoas, A. C. Lordsleem Júnior, I. B. T. A. Schmitz, V. M. Jonh. Reaproveitamento do resíduo de gesso na execução de revestimento interno de vedação vertical. Ambiente Construído, Porto Alegre, v. 10, n. 1, p. 103-119, 2010.

[11] G. L. Vieira, A. P. Trovão, C. R. Teles. Perspective of environmental sustainability with waste recycling plaster in construction. 
In: Sixteenth International Waste

Management and Landfill Symposium,

Proceedings Sardinia, Italy, 2017.

[12] C. V. Santana. Avaliação de desempenho de blocos fabricados com gesso reciclado em processo industrial. 2018. 116 f. Dissertação (Mestrado) - Faculdade de Engenharia Civil da Escola Politécnica de Pernambuco da Universidade de Pernambuco, 2018.

[13] ASSOCIAÇÃO BRASILEIRA DE NORMAS TÉCNICAS. NBR 15575-4. Edificações habitacionais - Desempenho. Parte 4: Requisitos para os sistemas de vedações verticais internas e externas - SVIE. Rio de Janeiro, 2013. 